\title{
Validation of a Weight Threshold-Based Vancomycin Dosing Protocol for Patients Undergoing Intermittent Hemodialysis
}

\author{
Lu Xuan (Lisa) Sun, Kang-Wei (David) Liu, Stephanie Lynch, Mielen Mistry, Heather Wise, \\ and Eduard Iliescu
}

\begin{abstract}
Background: Patients receiving intermittent hemodialysis (IHD) are at high risk of acquiring gram-positive infections, which are often treated with IV vancomycin. Despite frequent use of vancomycin in the IHD setting, there is variability in dosing and monitoring practices among clinicians at the study institution. There is also a paucity of evidence regarding optimal vancomycin dosing to achieve target pre-IHD serum concentration.
\end{abstract}

Objectives: The primary objective was to compare the percentage of treatment courses with a serum vancomycin concentration between 15 and $20 \mathrm{mg} / \mathrm{L}$, measured before the third IHD session, before and after implementation of a weight threshold-based dosing protocol. The secondary objectives were to compare the percentage of treatment courses with a pre-third IHD vancomycin concentration between 10 and $22 \mathrm{mg} / \mathrm{L}$ and the number of vancomycin measurements per treatment day, before and after protocol implementation.

Methods: This quasi-experimental, single-centre study included inpatients and outpatients who underwent IHD and received at least 2 IV doses of vancomycin, with vancomycin being measured in an appropriately drawn sample before the third IHD session. Before protocol implementation, vancomycin dosing was at the clinician's discretion (usual care). After protocol implementation, each patient received a loading dose of 1000,1500 , or $2000 \mathrm{mg}$ and a maintenance dose of 500,750 , or $1000 \mathrm{mg}$, depending on body weight.

Results: The percentage of treatment courses with a pre-third IHD vancomycin concentration between 15 and $20 \mathrm{mg} / \mathrm{L}$ was greater after implementation of the protocol than with usual care, but the difference was nonsignificant (44\% [8/18] versus 20\% [3/15], $p=0.27)$. However, the percentage of treatment courses with a pre-third IHD vancomycin concentration between 10 and $22 \mathrm{mg} / \mathrm{L}$ was significantly higher after protocol implementation $(94 \%[17 / 18]$ versus $53 \%$ [8/15], $p=0.012)$. There was no difference in the median number of vancomycin measurements per treatment day before and after protocol implementation $(0.133$ versus $0.125, p=0.99)$.

Conclusions: At the study institution, the likelihood of achieving recommended vancomycin concentration increased (relative to previous practice) after implementation of a simplified vancomycin dosing protocol for patients undergoing IHD.

\section{RÉSUMÉ}

Contexte : Les patients recevant une hémodialyse intermittente (HDI) présentent un risque élevé de contracter des infections à Gram positif, souvent traitées à l'aide de vancomycine par intraveineuse (IV). Malgré l'utilisation fréquente de la vancomycine dans les environnements d'HDI, les pratiques portant sur le dosage et le suivi varient entre les cliniciens de l'institution où l'étude s'est déroulée. Il existe également peu de données probantes sur la dose optimale de vancomycine permettant d'atteindre la concentration sérique cible avant l'HDI.

Objectifs : L'objectif principal visait à comparer le pourcentage de traitements à la vancomycine, dont la concentration sérique se situait entre 15 et $20 \mathrm{mg} / \mathrm{L}$, lors de la mesure prise avant la troisième séance de HDI, avant et après la mise en place d'un protocole de dosage basé sur le poids. Les objectifs secondaires visaient à comparer le pourcentage de traitements, dont la concentration de vancomycine mesurée avant la troisième séance d'HDI était comprise entre 10 et $22 \mathrm{mg} / \mathrm{L}$, et le nombre de mesures de vancomycine par jour de traitement, avant et après la mise en place du protocole.

Méthodes : Cette étude quasi expérimentale, menée dans un seul centre, comprenait des patients hospitalisés et ambulatoires ayant subi une HDI et reçu au moins deux doses de vancomycine par IV et dont un échantillon prélevé de manière appropriée avant la troisième séance d'HDI a permis de mesurer la vancomycine. Avant la mise en place du protocole, le dosage de vancomycine était laissé à la discrétion du clinicien (soins habituels). Après sa mise en place, chaque patient recevait une dose de charge de 1000, 1500 ou $2000 \mathrm{mg}$ et une dose de maintenance de 500, 750 ou $1000 \mathrm{mg}$ selon sa masse corporelle.

Résultats : Le pourcentage de traitements dont la concentration de vancomycine mesurée avant la troisième séance d'HDI était comprise entre 15 et $20 \mathrm{mg} / \mathrm{L}$ était plus élevé après la mise en place du protocole qu'après les soins habituels, mais la différence n'était pas significative ( $44 \%$ [8/18] contre $20 \%$ [3/15], $p=0,27)$. Cependant, le pourcentage de traitements dont la concentration de vancomycine mesurée avant la troisième séance d'HDI était comprise entre 10 et $22 \mathrm{mg} / \mathrm{L}$ était significativement plus élevé après la mise en place du protocole $(94 \%$ [17/18] contre $53 \%$ [8/15], $p=0,012)$. Le nombre moyen de mesures de vancomycine par traitement n'avait pas varié entre le jour précédant et le jour suivant la mise en place du protocole $(0,133$ contre 0,125 , $p=0,99)$. 
Keywords: vancomycin, dialysis, therapeutic drug monitoring, serum concentration, drug levels, dosing protocol

\section{Can J Hosp Pharm. 2019;72(5):369-76}

Conclusions : Dans l'institution où l'étude s'est déroulée, la probabilité d'atteindre la concentration de vancomycine recommandée avait augmenté après la mise en place d'un protocole simplifié de dosage de vancomycine pour les patients recevant une HDI comparativement à une pratique antérieure.

Mots-clés : vancomycine, dialyse, suivi thérapeutique pharmacologique, concentration sérique, concentrations du médicament, protocole de dosage

\section{INTRODUCTION}

$\mathrm{I}$ nfection is the second leading cause of death among patients receiving intermittent hemodialysis (IHD), with most infections being related to vascular access. ${ }^{1}$ In patients receiving IHD, Staphylococcus aureus is the leading pathogen, accounting for $27 \%$ to $39 \%$ of all cases of bacteremia. ${ }^{2}$ The risk of infection with invasive methicillin-resistant $S$. aureus (MRSA) is 100-fold higher in patients receiving IHD than in the general population; thus, vancomycin use is frequently warranted. ${ }^{3}$

There is a lack of evidence to support definitive recommendations on optimal targets for serum vancomycin concentration in the IHD population. Available evidence suggests that in the general population, exposure to vancomycin at serum trough concentrations less than $10 \mathrm{mg} / \mathrm{L}$ can produce $S$. aureus strains with characteristics similar to vancomycin-intermediate $S$. aureus. ${ }^{4}$ Therefore, the 2009 guideline of the Infectious Diseases Society of America (IDSA) recommended that serum trough concentrations of vancomycin be consistently maintained above $10 \mathrm{mg} / \mathrm{L}$ to prevent the development of resistance. ${ }^{4}$ For bacteremia and complicated infections, such as osteomyelitis, meningitis, hospital-acquired pneumonia, and infective endocarditis caused by MRSA, the IDSA guideline further recommended targeting vancomycin trough concentrations between 15 and $20 \mathrm{mg} / \mathrm{L} .{ }^{4}$ Trough concentrations within this range should achieve a ratio of area under the curve to minimum inhibitory concentration (AUC/MIC) of at least 400 in most patients, provided that the pathogen's MIC is no greater than $1 \mathrm{mg} / \mathrm{L}$. More specifically, for patients receiving IHD, most studies have targeted preIHD vancomycin concentrations of either $10-20 \mathrm{mg} / \mathrm{L}$ or 15-20 mg/L. ${ }^{5-12}$ These targets have also been adopted at the Kingston Health Sciences Centre (KHSC), where this study was conducted, with the latter being used for all patients with MRSA infection. However, recently published literature has suggested that a value of 18.6 or higher for the ratio of pre-IHD concentration to MIC is a predictor of positive clinical outcomes in treating MRSA bacteremia. ${ }^{13}$ In view of susceptibility data from Ontario, where the MIC of vancomycin for MRSA ranges between 0.5 and $1 \mathrm{mg} / \mathrm{L}$, a target between 9.3 and $18.6 \mathrm{mg} / \mathrm{L}$ for pre-IHD vancomycin concentration may be reasonable. ${ }^{14}$
An upper threshold for optimal pre-IHD vancomycin targets has not been well defined in existing guidelines, nor has a threshold been explicitly reported in the literature. In the general population, vancomycin use has been linked to nephrotoxicity, especially at high trough concentrations. ${ }^{3}$ On the basis of extrapolation from existing studies, high pre-IHD vancomycin concentrations are avoided at KHSC in an effort to preserve any residual renal function, which is associated with greater patient survival. ${ }^{15}$

The optimal sampling time for pre-IHD measurement of vancomycin has been poorly defined, and suggested approaches vary considerably in clinical practice. The half-life of vancomycin in patients with stage 5 chronic kidney disease can reach $180 \mathrm{~h}$ and is highly dependent on residual renal function in patients receiving IHD, making it difficult to routinely obtain true steady-state concentrations. ${ }^{16}$ The draft 2019 update of the IDSA guideline suggests measuring vancomycin concentration no less than once weekly; however, it does not offer specific recommendations on sampling time in relation to timing of the dialysis session. ${ }^{17}$ At KHSC, samples are routinely drawn before the third IHD session, to ensure that a vancomycin concentration is obtained within the first week of therapy.

Dosing of vancomycin in the setting of IHD varies considerably both in the studies reported in the literature and in practice. For much of the existing literature evaluating vancomycin dosing protocols, multiple vancomycin measurements were required to establish the dosing regimen for each patient, thus limiting their practicality. 7,10,12,18 Zelenitsky and others ${ }^{5}$ and Maxson and others ${ }^{6}$ evaluated fixed weight-based dosing protocols, but they were unable to achieve therapeutic targets in many patients. The draft 2019 IDSA guideline update offers specific suggestions for both intradialytic and post-IHD loading and maintenance doses. ${ }^{17}$ However, variability in medication administration practices for KHSC inpatients may hinder the ability to prescribe and administer the appropriate dose as per guideline recommendations. A standardized dosing approach for both outpatients and inpatients is therefore preferable at KHSC.

The purpose of this study was to standardize vancomycin dosing in the setting of IHD by building upon previously 
investigated vancomycin dosing protocols. The goal was to evaluate the efficacy of a simplified weight threshold-based vancomycin IHD dosing protocol (Table 1) at KHSC using a pragmatic approach to both dosing and monitoring of vancomycin.

\section{METHODS}

\section{Study Design and Population}

The study was approved by the Queen's University Health Sciences and Affiliated Teaching Hospitals Research Ethics Board before data collection. It was a quasi-experimental study at an academic tertiary care hospital, with retrospective chart review of patients in the pre-intervention period, followed by prospective evaluation of the dosing protocol during the post-intervention period.

The study included inpatients and outpatients receiving IHD at KHSC and selected satellite hemodialysis units, who received at least 2 IV doses of vancomycin and for whom vancomycin concentration was measured in an appropriately drawn sample before the third IHD session. Concentration values as measured in samples drawn up to $12 \mathrm{~h}$ before the third IHD session were included. Pre-intervention treatment courses were identified from a historical cohort of patients who underwent IHD from October 1, 2016, to April 30, 2017, and postintervention treatment courses were identified prospectively from October 1, 2017, to April 30, 2018. Treatment courses were excluded if continuous renal replacement therapy or peritoneal dialysis was used after initiation of vancomycin therapy, before the sample was drawn for measurement of pre-third IHD vancomycin concentration. In the post-intervention period, treatment courses that did not follow the dosing protocol were excluded. Most of the patients in both groups received IHD 3 or 4 times weekly. All patients underwent dialysis with high-flux membranes (FX HDF 800 [Fresenius Medical Care, Homburg, Germany] or Exeltra 170 [Baxter Healthcare Corporation, Deerfield, Illinois]).

\section{Data Collection}

Eligible treatment courses were identified through electronic patient care and pharmacy systems. Lists of patients receiving both IHD and vancomycin were generated from the pharmacy system, and administration of specific vancomycin doses was confirmed through medication administration records.

\section{Vancomycin Dosing Protocol and Blood Sampling for Determination of Vancomycin Concentrations}

During the pre-intervention period, vancomycin dosing in patients receiving IHD was based on a combination of individual clinician discretion and previous institutional vancomycin dosing guidelines. The previous institutional guidelines recommended a

\section{Table 1. Weight Threshold-Based Dosing Protocol}

\begin{tabular}{lcc} 
Weight* & $\begin{array}{c}\text { Loading } \\
\text { Dose }(\mathbf{m g})\end{array}$ & $\begin{array}{c}\text { Maintenance } \\
\text { Dose }(\mathbf{m g})\end{array}$ \\
\hline$<70 \mathrm{~kg}$ & 1000 & 500 \\
$70-100 \mathrm{~kg}$ & 1500 & 750 \\
$>100 \mathrm{~kg}$ & 2000 & 1000 \\
\hline *Dry weight. & \multicolumn{2}{c}{}
\end{tabular}

loading dose of $20 \mathrm{mg} / \mathrm{kg}$ rounded to the nearest $250 \mathrm{mg}$, followed by an initial maintenance dose of $500 \mathrm{mg}$ administered either after IHD (inpatients) or during the remaining $30 \mathrm{~min}$ of dialysis (outpatients). The maintenance dose was subsequently adjusted as needed by increments or decrements of $250 \mathrm{mg}$ on the basis of pre-IHD concentrations targeted between 8 and $20 \mathrm{mg} / \mathrm{L}$. These previous guidelines did not recommend a specific sampling time for pre-IHD vancomycin concentrations.

During the post-intervention period, vancomycin dosing was based on weight thresholds, whereby patients with body weight less than $70 \mathrm{~kg}$ received a loading dose of $1000 \mathrm{mg}$, followed by a maintenance dose of $500 \mathrm{mg}$; patients with body weight between 70 and $100 \mathrm{~kg}$ received a loading dose of $1500 \mathrm{mg}$, followed by a maintenance dose of $750 \mathrm{mg}$; and patients with body weight greater than $100 \mathrm{~kg}$ received a loading dose of 2000 $\mathrm{mg}$, followed by a maintenance dose of $1000 \mathrm{mg}$ (Table 1). For inpatients, the loading and maintenance doses could be given either after dialysis or during dialysis, timed to end with the dialysis session. In all outpatients, the loading and maintenance doses were administered during dialysis and were timed to end with the dialysis session. Vancomycin was administered at a rate of $1000 \mathrm{mg} / \mathrm{h}$. Samples were drawn for pre-IHD measurement of vancomycin concentration before the third dialysis session.

\section{Protocol Implementation}

During protocol implementation, the proposed loading and maintenance doses were pre-populated in the patient care system of the outpatient hemodialysis unit, with corresponding weight ranges shown in brackets, to facilitate selection of the appropriate doses during prescribing by computerized physician order entry. The institutional vancomycin dosing and monitoring guidelines were updated with the study dosing protocol. This served to facilitate prescribing of IV vancomycin within the paper-based system for inpatients receiving IHD. Pharmacists reviewed inpatient vancomycin orders and intervened as needed to ensure that the dosing protocol was followed, as clinically appropriate. Education was also provided to the physicians and other staff implicated in this study through in-person presentations and e-mail communications. Reference cards detailing the weight threshold-based dosing protocol were also circulated to hemodialysis units. 


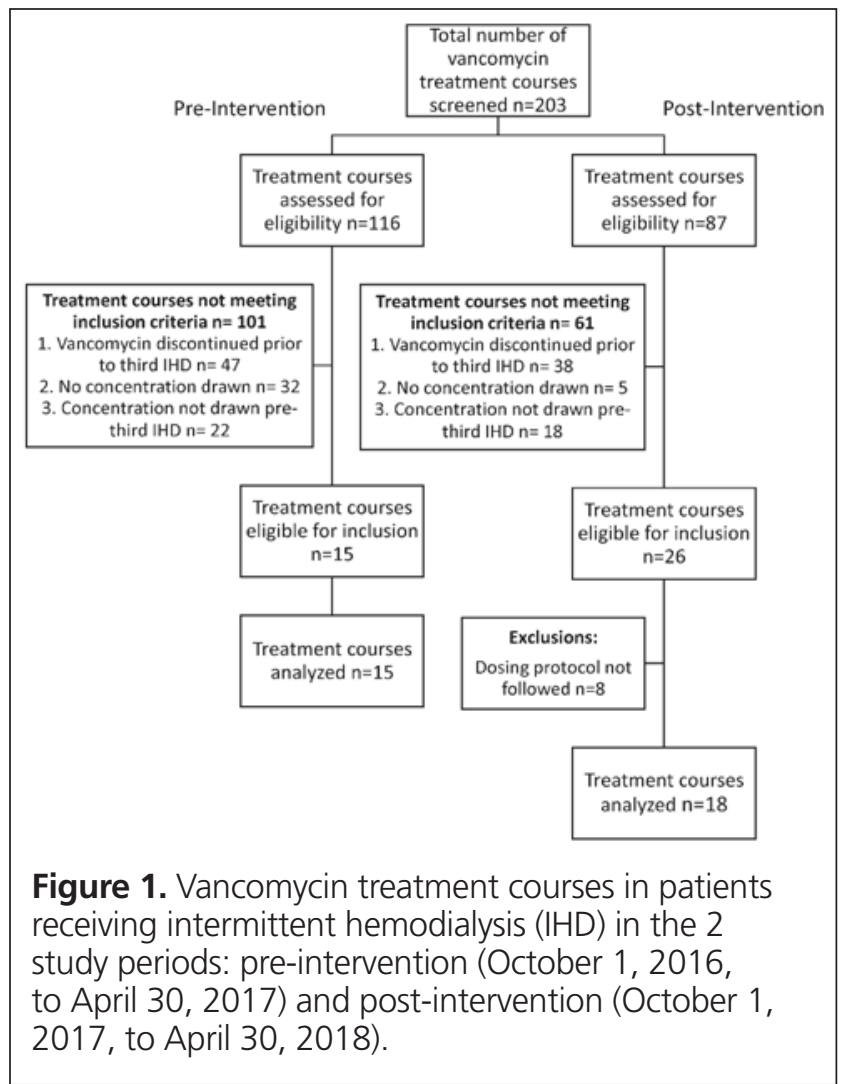

\section{Study Outcomes}

The primary outcome was the difference in percentage of treatment courses with pre-third IHD vancomycin concentrations between 15 and $20 \mathrm{mg} / \mathrm{L}$, before and after protocol implementation. Secondary outcomes were the differences between the 2 groups in the percentage of treatment courses with pre-third IHD vancomycin concentrations between 10 and $22 \mathrm{mg} / \mathrm{L}$, as well as the number of samples drawn for measurement of vancomycin concentration per day of vancomycin treatment while receiving IHD. The upper limit of $22 \mathrm{mg} / \mathrm{L}$ was selected a priori, after taking into consideration the lower clinical concern about high vancomycin concentrations in this patient population among KHSC nephrologists and information in the existing literature. ${ }^{5}$ It was hypothesized that the new dosing protocol would result in more frequent attainment of vancomycin concentration within the desired range, which would lead clinicians to order fewer pre-IHD measurements of vancomycin concentration and hence create potential resource savings.

\section{Statistical Analysis}

Analysis was performed with IBM SPSS version 24.0 (IBM Corporation, Armonk, New York). For study outcomes involving proportions of treatment courses with vancomycin concentration reaching the target ranges, the Fisher exact test was used to evaluate the difference between the pre-intervention and post-

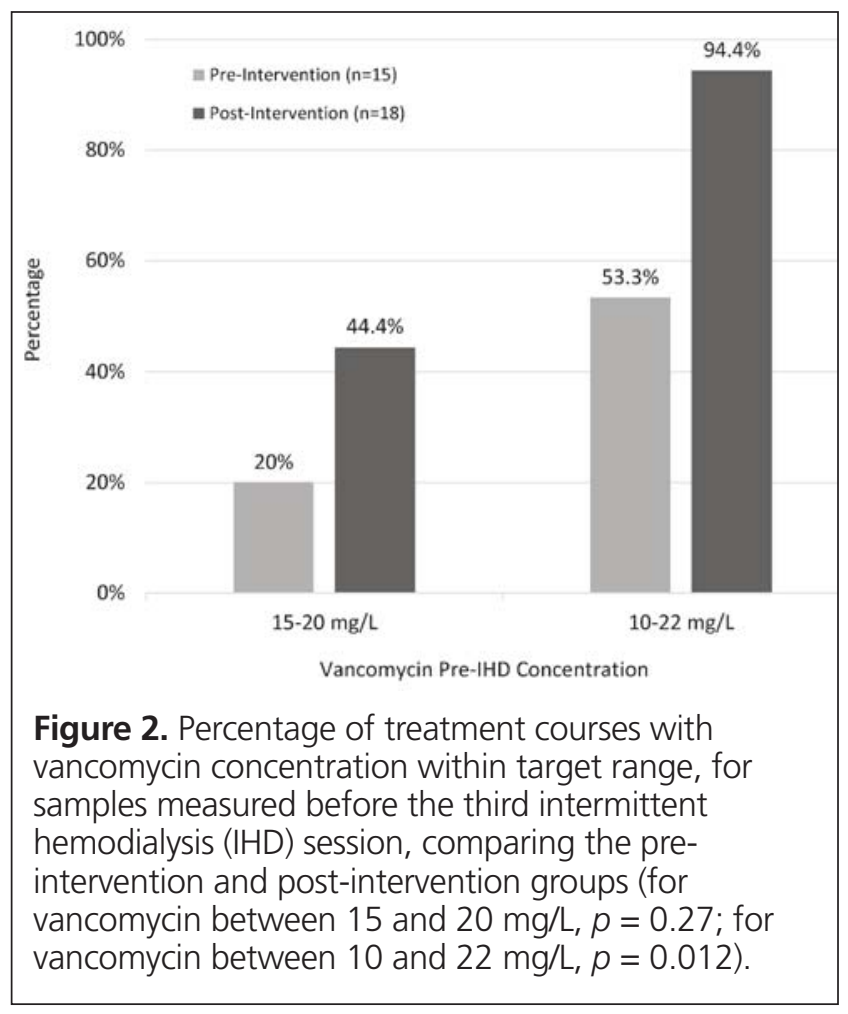

intervention groups. The number of measurements per day of vancomycin treatment was analyzed with the Mann-Whitney $U$ test. A $p$ value less than 0.05 was considered statistically significant.

\section{RESULTS}

A total of 203 vancomycin treatment courses were screened for inclusion in this study. Fifteen treatment courses (from 14 unique patients) in the pre-intervention group and 18 treatment courses (from 16 unique patients) in the post-intervention group were included for analysis (Figure 1). In the post-intervention group, 8 treatment courses were excluded because the study dosing protocol was not followed. Baseline characteristics were similar between the 2 groups, as was the distribution between inpatients and outpatients (Table 2). The median loading dose was significantly higher in the post-intervention group than in the pre-intervention group $(19.36 \mathrm{mg} / \mathrm{kg}$ and $13.33 \mathrm{mg} / \mathrm{kg}$, respectively, $p=0.012$ ). The median maintenance dose was similar for the 2 groups $(9.68 \mathrm{mg} / \mathrm{kg}$ and $9.62 \mathrm{mg} / \mathrm{kg}$, respectively). In most cases (29 of 33 [88\%]), samples for pre-third IHD vancomycin measurement were drawn within an hour before the start of dialysis.

In terms of the primary outcome, pre-third IHD vancomycin concentrations between 15 and $20 \mathrm{mg} / \mathrm{L}$ were achieved in $8(44 \%)$ of 18 treatment courses after implementation of the simplified dosing protocol, compared with $3(20 \%)$ of 15 treatment courses before the intervention $(p=0.27)$ (Figure 2). In terms of the secondary outcomes, pre-third IHD vancomycin 
Table 2. Baseline Characteristics

\begin{tabular}{|c|c|c|}
\hline \multirow[b]{2}{*}{ Characteristic } & \multicolumn{2}{|c|}{ No. $(\%)$ of Treatment Courses*† } \\
\hline & $\begin{array}{l}\text { Pre-implementation } \\
(n=15)\end{array}$ & $\begin{array}{l}\text { Post-implementation } \\
\qquad(n=18)\end{array}$ \\
\hline Age (years) (median) & 68 & 62 \\
\hline \multicolumn{3}{|l|}{ Body weight $\neq$} \\
\hline$<70 \mathrm{~kg}$ & $4 \quad(27)$ & $2(11)$ \\
\hline $70-100$ kg & $8 \quad(53)$ & $10 \quad(56)$ \\
\hline$>100 \mathrm{~kg}$ & $3(20)$ & $6 \quad(33)$ \\
\hline Sex, male & $9 \quad(60)$ & $10 \quad(56)$ \\
\hline Inpatients & $10 \quad(67)$ & $9 \quad(50)$ \\
\hline \multicolumn{3}{|c|}{$\begin{array}{l}\text { Dose of vancomycin (mg/kg) } \\
\text { (median and IQR) }\end{array}$} \\
\hline Loading & 13.33 (10.42-19.23) & $19.36(15.81-19.75)$ \\
\hline Maintenance & $9.62 \quad(7.08-13.33)$ & $(7.91-9.88)$ \\
\hline \multicolumn{3}{|c|}{$\begin{array}{l}\text { *For the pre-implementation group, the } 15 \text { treatment courses involved a total of } \\
14 \text { patients. For the post-implementation group, the } 18 \text { treatment courses involved } \\
\text { a total of } 16 \text { patients. As such, some patients were double-counted in the proportions } \\
\text { reported here. } \\
\text { tExcept where indicated otherwise. } \\
\text { fDry weight. }\end{array}$} \\
\hline
\end{tabular}

concentrations between 10 and $22 \mathrm{mg} / \mathrm{L}$ were achieved in 17 (94\%) of 18 treatment courses after the intervention, compared with $8(53 \%)$ of 15 treatment courses before the intervention $(p=0.012)$. The median number of samples drawn for measurement of vancomycin concentration per treatment day was similar between the pre- and post-intervention groups ( 0.133 versus $0.125, p=0.99)$.

The spread between pre- and post- intervention groups in terms of pre-third IHD vancomycin concentration is illustrated in Figure 3. The median vancomycin concentration achieved was 10.4 (interquartile range [IQR] $8.1-16.1$ ) $\mathrm{mg} / \mathrm{L}$ in the preintervention group and 13.6 (IQR $11.4-17.1) \mathrm{mg} / \mathrm{L}$ in the postintervention group. Among all treatment courses included in the post-intervention group, the highest vancomycin concentration achieved was $21.2 \mathrm{mg} / \mathrm{L}$.

The spread between groups in terms of the pre-third IHD vancomycin concentration was further examined by separating the data according to the 3 weight threshold categories outlined in the dosing protocol (Figure 4). For vancomycin courses in the pre-intervention group for patients weighing $70 \mathrm{~kg}$ or more, $18 \%(2 / 11)$ and $45 \%(5 / 11)$ of pre-third IHD vancomycin concentrations were within the target ranges of 15-20 and $10-22 \mathrm{mg} / \mathrm{L}$, respectively. Correspondingly, in the post-intervention group, $50 \%(8 / 16)$ and $94 \%(15 / 16)$ of pre-third IHD vancomycin concentrations were within the target ranges of 15-20 and 10-22 $\mathrm{mg} / \mathrm{L}$, respectively. No supratherapeutic concentrations, defined as a concentration greater than $22 \mathrm{mg} / \mathrm{L}$, were observed in any weight category within the post-intervention group.

\section{DISCUSSION}

The results of this study demonstrated the feasibility of a pragmatic, weight threshold-based vancomycin dosing protocol for patients receiving IHD. The study data revealed a numerically higher percentage of treatment courses with pre-IHD vancomycin concentrations between 15 and $20 \mathrm{mg} / \mathrm{L}$, and a statistically significantly higher percentage of treatment courses with pre-IHD vancomycin concentrations between 10 and $22 \mathrm{mg} / \mathrm{L}$, after implementation of the weight threshold-based dosing protocol. The results of this study were consistent with those of the study conducted by Zelenitsky and others, ${ }^{5}$ in which approximately $90 \%$ of measured values for pre-IHD vancomycin concentration after administration of a loading dose and at least one maintenance dose were within the range of 10 to $22 \mathrm{mg} / \mathrm{L}$, and approximately $40 \%$ of the measured values were between 15 and $20 \mathrm{mg} / \mathrm{L}$.

The dosing and monitoring of vancomycin in the setting of IHD remains challenging. Patients with differing clinical presentations, such as admission status, severity of infectious disease, and baseline residual renal function, have been studied, often with each study evaluating slightly different dosing, timing of vancomycin administration, and concentration sampling times. ${ }^{5-7,9,11,18,19}$ In addition, several studies have evaluated only loading doses. ${ }^{8,16}$ For these reasons, it is difficult to synthesize a dosing and monitoring strategy that can be conveniently applied to routine clinical practice.

During development of the study's dosing protocol and monitoring plan, studies by Zelenitsky and others ${ }^{5}$ and Maxson and others $^{6}$ were closely examined. Zelenitsky and others ${ }^{5}$ prospectively evaluated a dosing protocol derived from Monte Carlo simulations. Patients with body weight less than $70 \mathrm{~kg}$, between 70 and $100 \mathrm{~kg}$, and greater than $100 \mathrm{~kg}$ received loading doses of 1000,1250 , and $1500 \mathrm{mg}$, respectively, and maintenance doses of 500, 750, and $1000 \mathrm{mg}$, respectively, infused during the last hour of dialysis. This protocol delivered mean loading and maintenance doses of 16 and $9.1 \mathrm{mg} / \mathrm{kg}$, respectively. We 


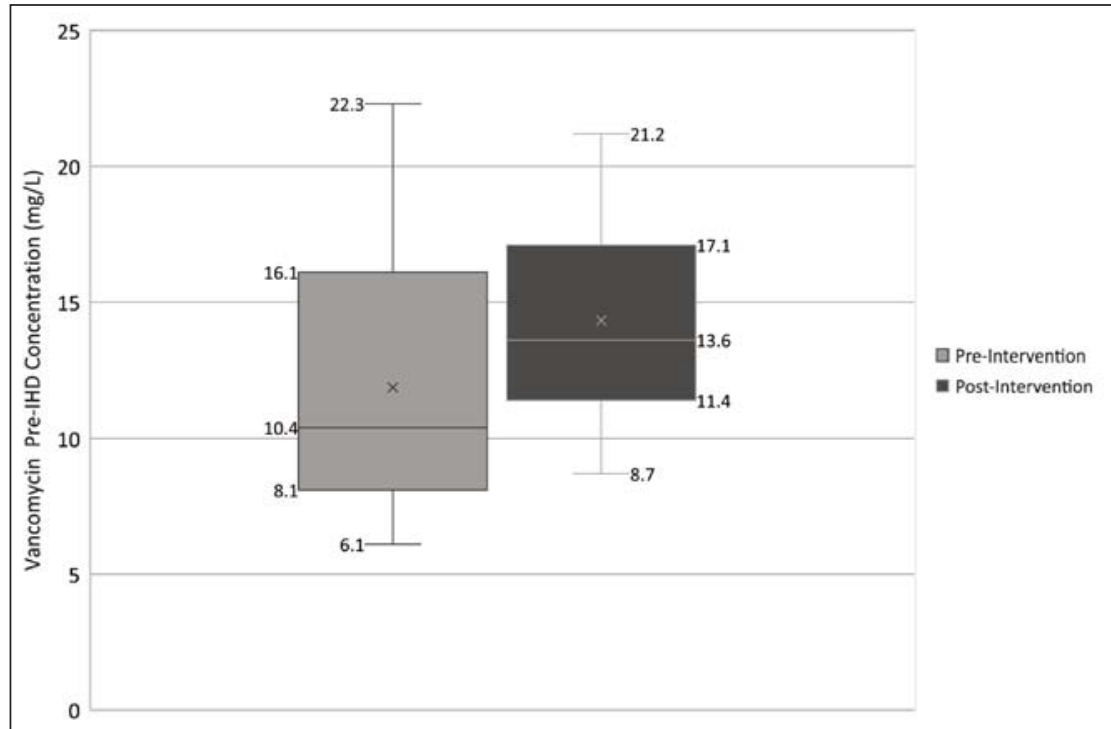

Figure 3. Distribution of vancomycin concentration, for samples measured before the third intermittent hemodialysis (IHD) session, shown as box and whisker plots for the pre-intervention and post-intervention groups. The median is represented by the horizontal line within the box, and the mean is represented by the symbol $x$ within the box. The box captures the middle $50 \%$ of the data, with the lower and upper boundaries indicating the 25th and 75th percentiles, respectively. The lower whisker extends to the smallest non-outlier data point and the upper whisker extends to the largest non-outlier data point. There were no outliers in these data.

hypothesized that the loading doses might have been too low, as $76.9 \%$ of pre-second IHD (post-load) concentration values were between 10 and $20 \mathrm{mg} / \mathrm{L}$, with only $34.6 \%$ between 15 and 20 $\mathrm{mg} / \mathrm{L}$. However, the maintenance doses used appeared to be adequate, as a considerable percentage of pre-IHD measurements between the third and seventh sessions were in the ranges of 10-22 mg/L (89.7\%) and 15-22 mg/L (62.1\%). Conversely, Maxson and others ${ }^{6}$ examined a fixed loading dose of $20 \mathrm{mg} / \mathrm{kg}$, followed by a weight-based maintenance dose up to $1250 \mathrm{mg}$, administered after dialysis in hospital inpatients. This dosing strategy resulted in a mean maintenance dose of $13.8 \mathrm{mg} / \mathrm{kg}$. Pre-IHD concentration of vancomycin over $20 \mathrm{mg} / \mathrm{L}$ was observed in more than $50 \%$ of patients with body weight above $75 \mathrm{~kg}$.

Building on these 2 studies, we designed a weight thresholdbased vancomycin dosing protocol for both loading and maintenance doses at KHSC. The loading dose was capped at $2000 \mathrm{mg}$ in the current study, as there is a lack of evidence examining intradialytic administration of vancomycin beyond the last $2 \mathrm{~h}$ of the dialysis session. ${ }^{20}$ The maintenance doses were selected on the basis of dosing strategies and resulting pre-IHD vancomycin concentrations in previous studies, ${ }^{5,69-11}$ with emphasis on those by Zelenitsky and others ${ }^{5}$ and Maxson and others. ${ }^{6}$ Overall, patients in the post-intervention group of the current study received a significantly higher loading dose, whereas the maintenance dose was comparable between the pre- and post-intervention groups (Table 2). The higher loading dose did not result in supratherapeutic pre-IHD vancomycin concentration (> $22 \mathrm{mg} / \mathrm{L}$ ) across weight categories. Despite variability among inpatients and outpatients with regard to volume status, acute disease state, residual renal function, or patient adherence to IHD therapy, the study's weight threshold-based dosing protocol resulted in more patients achieving target pre-IHD vancomycin concentration, and therefore represents a reasonable and practical approach to vancomycin dosing for patients receiving IHD at KHSC.

In this study, we examined vancomycin concentration as measured in samples drawn before the third IHD session. With acknowledgement that a steady state would not likely be achieved before treatment completion, the pre-third IHD vancomycin concentration nevertheless provides useful information, reflecting the contribution of both loading and maintenance doses to the observed concentration and ensuring the availability of a vancomycin concentration within the first week of treatment to direct subsequent dosing. ${ }^{4,5}$

One of the study's secondary outcomes attempted to capture potential cost savings, by determining whether there was a reduction in the number of pre-IHD vancomycin measurements 


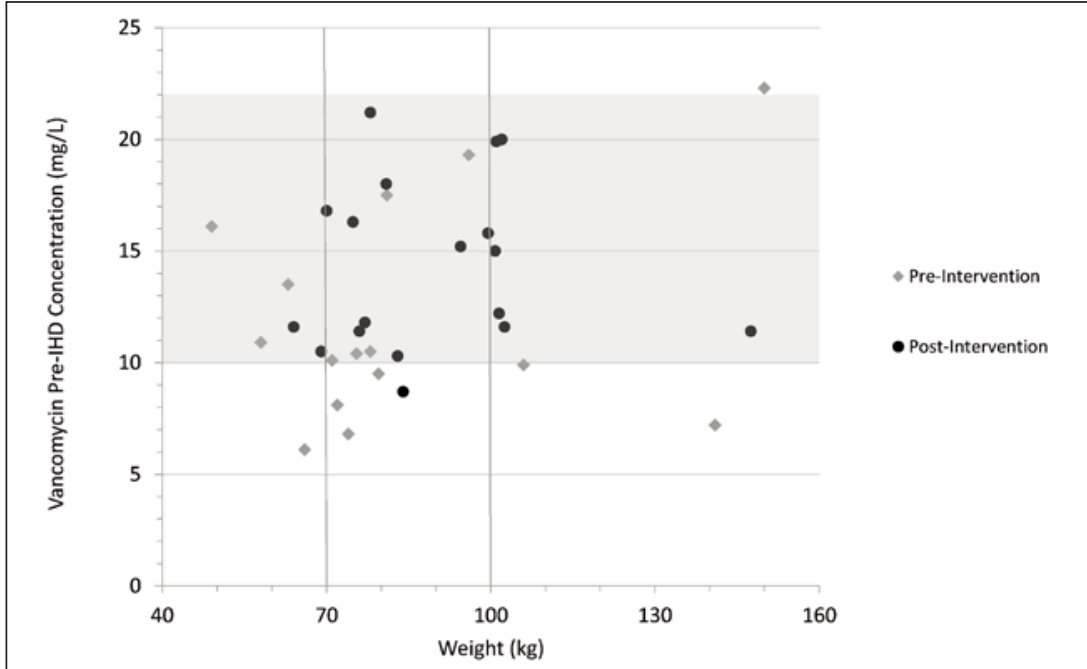

Figure 4. Scatter plot of vancomycin concentration, for samples measured before the third intermittent hemodialysis (IHD) session, by body weight. The pre-intervention $(n=15)$ and post-intervention $(n=18)$ data points are shown within 3 weight categories: $<70$ kg, 70-100 kg, and $>100 \mathrm{~kg}$. For post-intervention treatment courses in patients with body weight less than $70 \mathrm{~kg}$, the pre-IHD concentrations were 10.5 and $11.6 \mathrm{mg} / \mathrm{L}$ (2 data points). For post-intervention treatment courses in patients between 70 and $100 \mathrm{~kg}$, the pre-IHD concentrations ranged from 8.7 to $21.2 \mathrm{mg} / \mathrm{L}$ (10 data points), with a median of $15.5 \mathrm{mg} / \mathrm{L}$. For post-intervention treatment courses in patients with body weight more than $100 \mathrm{~kg}$, the pre-IHD concentrations ranged from 11.4 to $20 \mathrm{mg} / \mathrm{L}$ (6 data points), with a median of $13.6 \mathrm{mg} / \mathrm{L}$.

required for ongoing monitoring after implementation of the protocol. However, there was no difference in the median number of vancomycin measurements obtained per day of vancomycin therapy before and after protocol implementation. We hypothesize that this result was largely due to the education provided about the study protocol, which may have improved clinicians' awareness of the requirement for regular monitoring of vancomycin concentration, which may not have been occurring routinely during the pre-intervention period.

This study had several limitations that should be considered. Potential confounders that may influence vancomycin concentration could not be completely controlled, including patients' residual renal function, vancomycin administration time relative to IHD, duration of each IHD session, the interdialytic interval, and dialysis vintage. Moreover, the small sample size may have limited the statistical power of the study and generalizability of the results. The study was performed at a single centre and therefore results may not be generalizable to other institutions, because of differences in clinical practice that may affect the dosing, administration, and monitoring of vancomycin therapy in patients receiving IHD. Lastly, pre-IHD vancomycin concentration represents a surrogate for clinical outcomes such as clinical or bacteriological cure. However, the main goal of this study was to validate the effect of the dosing protocol in achieving desired pre-IHD vancomycin concentration.

Despite differences between patients, the smaller spread in pre-IHD vancomycin concentration after implementation of the dosing protocol demonstrated more reliable attainment of concentrations within the target range (Figure 3). In patients weighing more than $70 \mathrm{~kg}$, the high proportion of pre-IHD vancomycin concentrations within the target range provides relative confidence in the applicability of the study's dosing protocol to this patient population (Figure 4). The totality of study results is hypothesis-generating, and future studies could be designed to evaluate higher maintenance doses, such as 750 and $1000 \mathrm{mg}$ for weight categories of less than $70 \mathrm{~kg}$ and $70-100 \mathrm{~kg}$, respectively, while keeping the loading dose unchanged.

\section{CONCLUSION}

This study demonstrated that a fixed, weight thresholdbased dosing protocol was effective and practical in achieving target pre-IHD vancomycin concentrations for both inpatients and outpatients undergoing IHD. The percentage of treatment courses with pre-IHD vancomycin concentrations between 10 and $22 \mathrm{mg} / \mathrm{L}$ was significantly higher after implementation of the protocol. Extension of the study duration, to increase patient 
enrolment and capture more patients with extremes of weight, may help to further validate this dosing protocol and identify areas where potential changes may be required.

\section{References}

1. Lafrance JP, Rahme E, Lelorier J, Iqabl S. Vascular access-related infections: definitions, incidence rates, and risk factors. Am J Kidney Dis. 2008;52(5): 982-93.

2. Vandecasteele SJ, Boelaert JR, De Vriese AS. Staphylococcus aureus infections in hemodialysis: what a nephrologist should know. Clin J Am Soc Nephrol. 2009; 4(8):1388-400.

3. Invasive methicillin-resistant Staphylococcus aureus infections among dialysis patients-United States, 2005. MMWR Morb Mortal Wkly Rep. 2007; 56(8):197-9.

4. Rybak M, Lomaestro B, Rotschafer JC, Moellering R Jr, Craig W, Billeter $\mathrm{M}$, et al. Therapeutic monitoring of vancomycin in adult patients: a consensus review of the American Society of Health-System Pharmacists, the Infectious Diseases Society of America, and the Society of Infectious Diseases Pharmacists. Am J Health Syst Pharm. 2009;66(1):82-98.

5. Zelenitsky SA, Ariano RE, McCrae ML, Vercaigne LM. Initial vancomycin dosing protocol to achieve therapeutic serum concentrations in patients undergoing hemodialysis. Clin Infect Dis. 2012;55(4):527-33.

6. Maxson R, Pate J, Starr J. Evaluation of weight-based vancomycin dosing for hospitalized hemodialysis patients. Renal Failure. 2016;38(10):1677-82.

7. Panais R, Hirsch DJ, Dipchand C, Storsley L, Finkle SN. A protocolized approach to vancomycin dosing in conventional hemodialysis. J Nephrol. 2010;23(5):569-74.

8. Brown M, Polisetty R, Gracely EJ, Cuhaci B, Schlecht HP. Weight-based loading of vancomycin in patients on hemodialysis. Clin Infect Dis. 2011:53(2):164-6.

9. Lin SY, Shen MC, Hwang SJ, Chen YH, Chen TC, Chiu YW, Lu PL. Evaluation of vancomycin dosing protocols to achieve therapeutic serum concentrations in patients receiving high-flux hemodialysis. Int J Antimicrob Agents. 2014;43(4):384-5.

10. Vandecasteele SJ, De Bacquer D, De Vriese AS. Implementation of a dose calculator for vancomycin to achieve target trough levels of $15-20 \mathrm{microg} / \mathrm{mL}$ in persons undergoing hemodialysis. Clin Infect Dis. 2011;53(2):124-9.

11. Taylor ME, Allon M. Practical vancomycin dosing in hemodialysis patients in the era of emerging vancomycin resistance: a single-center experience. $\mathrm{Am}$ J Kidney Dis. 2010;55(6):1163-5.

12. El Nekidy WS, El-Masri MM, Umstead GS, Dehoorne-Smith M. Predicting maintenance doses of vancomycin for hospitalized patients undergoing hemodialysis. Can J Hosp Pharm. 2016;69(5):341-7.

13. Fu CF, Huang JD, Wang JT, Lin SW, Wu CC. The ratio of pre-dialysis vancomycin trough serum concentration to minimum inhibitory concentration is associated with treatment outcomes in methicillin-resistant Staphylococcus aureus bacteremia. PLoS One. 2018;13(3):e0193585.

14. 2017 Ontario antimicrobial susceptibility testing results: Staphylococcus aureus, MRSA. Winnipeg (MB): Canadian Antimicrobial Resistance Alliance; [cited 2019 May 1]. Available from: http://www.can-r.com/ study.php?study=canw2017\&year $=2017$

15. Obi Y, Streja E, Rhee CM, Ravel V, Amin AN, Cupsiti A, et al. Incremental hemodialysis, residual kidney function, and mortality risk in incident dialysis patients: a cohort study. Am J Kidney Dis. 2016;68(2):256-65.

16. El Nekidy WS, El-Masri MM, Umstead GS, Dehoorne-Smith M. Factors influencing vancomycin loading dose for hospitalized hemodialysis patients: prospective observational cohort study. Can J Hosp Pharm. 2012; 65(6):436-42.
17. Ryback MJ, Le J, Lodise TP, Levine DP, Bradley JS, Liu C, et al. Therapeutic monitoring of vancomycin: a revised consensus guideline and review of the American Society of Health-System Pharmacists, the Infectious Diseases Society of America, the Pediatric Infectious Diseases Society and the Society of Infectious Diseases Pharmacists [draft]. Bethesda (MD): American Society of Health-System Pharmacists; [cited 2019 May 16]. Available from: https://www.ashp.org/-/media/assets/policy-guidelines/docs/draftguidelines/draft-guidelines-ASHP-IDSA-PIDS-SIDP-therapeuticvancomycin.ashx?la=en\&hash=8126CEE49F401CDEE5DB49712225F0A 4518DB94B. Projected publication: fall 2019

18. Pai AB, Pai MP. Vancomycin dosing in high flux hemodialysis: a limitedsampling algorithm. Am J Health Syst Pharm. 2004;61(17):1812-6.

19. Ariano RE, Fine A, Sitar DS, Rexrode S, Zelenitsky SA. Adequency of a vancomycin dosing regimen in patients receiving high-flux hemodialysis. Am J Kidney Dis. 2005;46(4):681-7.

20. Mason NA, Neudeck BL, Welage LS, Patel JA, Swartz RD. Comparison of 3 vancomycin dosage regimens during hemodialysis with cellulose triacetate dialyzers: post-dialysis versus intradialytic administration. Clin Nephrol. 2003;60(2):96-104.

Lu Xuan (Lisa) Sun, PharmD, RPh, ACPR, is a Clinical Pharmacist with Kingston Health Sciences Centre, Kingston, Ontario.

Kang-Wei (David) Liu, BScPhm, PharmD, RPh, MPH, BCPS, was, at the time of this study, a Clinical Pharmacist (General Medicine) with Kingston Health Sciences Centre, Kingston, Ontario. He is now the Director of Pharmacy at Norfolk General Hospital, Simcoe, Ontario, and West Haldimand General Hospital, Hagersville, Ontario.

Stephanie Lynch, BSC(Pharm), RPh, ACPR, PharmD, BCACP, is a Clinical Pharmacist (Nephrology) with Kingston Health Sciences Centre, Kingston, Ontario.

Mielen Mistry, BScPhm, RPh, ACPR, is a Clinical Pharmacist (General Medicine) with Kingston Health Sciences Centre, Kingston, Ontario.

Heather Wise, BSC(Pharm), RPh, ACPR, is a Clinical Pharmacist (Critical Care/Infectious Diseases) with Kingston Health Sciences Centre, Kingston, Ontario.

Eduard Iliescu, MD, BSC, MSC, FRCPC, FACP, FASN, is the Medical Director Hemodialysis, Kingston Health Sciences Centre and Satellites, Kingston, Ontario. He is also Regional Medical Lead for the South East Local Health Integration Network and the Ontario Renal Network.

Competing interests: None declared.

\section{Address correspondence to:}

Dr Lu Xuan (Lisa) Sun

Department of Pharmacy Services

Kingston Health Sciences Centre

76 Stuart Street

Kingston ON K7L 2V7

e-mail: lisa.sun@kingstonhsc.ca

Funding: None received.

Acknowledgements: The authors thank Wilma Hopman for her assistance with statistical analysis. 